Laurenz Lütteken (Zürich)

\title{
Zum Gedenken an Max Lütolf (1934-2015)
}

Dem akademischen Betrieb mit all seinen Unwägbarkeiten stand Max Lütolf immer mit einer gewissen Skepsis gegenüber, einer allerdings heiteren, zurückhaltenden und wohlwollenden Skepsis. Diese diskrete Distanz zu den Dingen verdankte sich vielleicht seiner Herkunft, die ihm alles näher gelegt hatte als ein Leben im Dienst der Musik. Max Lütolf wurde am 1. Dezember 1934 in Altishofen geboren, einem winzigen Dorf im Luzerner Hinterland. Im bäuerlich-ländlichen Umfeld seiner Heimat fiel die musikalische Begabung jedoch bald auf, die Beschäftigung mit der liturgischen Musik und der lebenslang geliebten Orgel wurde vor allem im Stanser Kollegium bei den Kapuzinern geweckt und gepflegt. Nach der Matur entschloss sich Lütolf, Musikwissenschaft zu studieren, zunächst in Fribourg, dann in Basel, bei Leo Schrade. Gleichwohl musste er das Studium unterbrechen, um als ältester Sohn für längere Zeit im elterlichen Betrieb auszuhelfen.

Als er 1967 in Basel mit einer Arbeit zu den mehrstimmigen Ordinariumsvertonungen des 12. und 13. Jahrhunderts promoviert wurde - einer zweibändigen Studie, die auch fünfzig Jahre später noch Referenzcharakter besitzt -, folgte eine kurze Assistentenzeit in Basel und dann der Wechsel an die Universität Zürich, wo er sich 1976 habilitiert hat, mit einer Studie zur mehrstimmigen Passionsvertonung in Italien. Während der Vorbereitungen hielt er sich erstmals für längere Zeit am römischen Istituto Svizzero auf, und damit war der Grundstein für eine lebenslange, leidenschaftliche Rom-Begeisterung gelegt.

1977 wurde er als außerordentlicher Professor an die Universität Zürich berufen, wo er ab 1988 als Ordinarius gelehrt und geforscht hat. Seine breit ausgreifenden wissenschaftlichen Interessen galten der liturgischen Musik im weitesten Sinne, mit einem besonderen Schwerpunkt im Mittelalter. Immer wieder hat er sich dabei mit großräumigen Editionsvorhaben befasst. So erstellte er das Register zur monumentalen Sammlung der Analecta hymnica, die damit erst benutzbar wurde; er edierte etliche mittelalterliche Handschriften, unter denen das sorgfältig kommentierte Faksimile des Graduale von S. Cecilia in Trastevere herausragt. Zudem hat er sich editorisch der Musik des römischen Barock gewidmet, unter anderem in seiner Ausgabe der Opera I und III von Arcangelo Corelli; und er hat die wissenschaftliche Ausgabe der Werke Othmar Schoecks begründet und geleitet, bis zu einem Zeitpunkt, als andere, von außen herangetragene Interessen das Projekt beeinträchtigt haben. Lütolf, dem solche Funktionalisierungen zuwider waren, zog sich umgehend zurück. So nutzte er alle Energie für das wohl umfangreichste der von ihm angestoßenen Editionsvorhaben, die acht Bände der Geistlichen Gesänge des deutschen Mittelalters, die kurz vor dem Abschluss stehen und deren Vollendung er nun nicht mehr erleben kann.

Max Lütolf, der auch für das Schweizer Orgelinventar verantwortlich zeichnete, wurde mehrfach geehrt, so mit der Dent Medal und dem Ehrendokotrat des päpstlichen Instituts für Kirchenmusik in Rom. Für ihn, den bekennenden Katholiken, schlossen sich Ratio und Affectus, Verstand und Musik, Wissenschaft und Spiritualität nicht aus. Dieser Haltung verdankte sich seine persönliche, von allen Kollegen und Mitarbeitern stets geschätzte Integrität. Seine letzten Jahre waren von schwerer Krankheit gezeichnet, verbunden mit dem voranschreitenden Abschied aus der Gegenwart. Max Lütolf verstarb am 23. November 2015, wenige Tage vor seinem 81. Geburtstag. 